\title{
Performance Evaluation Criterion at Equal Pumping Power for Enhanced Performance Heat Transfer Surfaces
}

\author{
Rajendra Karwa, ${ }^{1}$ Chandresh Sharma, ${ }^{2}$ and Nitin Karwa ${ }^{3}$ \\ ${ }^{1}$ JIET School of Engineering \& Technology for Girls, Mogra, NH 65, Jodhpur, Rajasthan 342002, India \\ ${ }^{2}$ Jodhpur National University, Narnadi, Jhanwar Road, Jodhpur, Rajasthan, India \\ ${ }^{3}$ Technical University Darmstadt, Darmstadt, Germany \\ Correspondence should be addressed to Rajendra Karwa; karwa_r@yahoo.com
}

Received 27 January 2013; Revised 1 May 2013; Accepted 15 May 2013

Academic Editor: Xin Wang

Copyright (c) 2013 Rajendra Karwa et al. This is an open access article distributed under the Creative Commons Attribution License, which permits unrestricted use, distribution, and reproduction in any medium, provided the original work is properly cited.

The existing equations for the thermal performance evaluation, at equal pumping power for the artificially roughened and smooth surfaced multitube and rectangular duct heat exchangers, have been critically reviewed because the literature survey indicates that a large number of researchers have not interpreted these equations correctly. Three of the most widely used equations have been restated with clearly defined constraints and conditions for their application. Two new equations have been developed for the design constraints not covered earlier.

\section{Introduction}

Artificial roughness in the form of ribs or baffles has been employed to enhance heat transfer in conventional heat exchangers, gas turbine blade cooling channels, and solar air heaters. However, the enhancement in heat transfer is also associated with significant increase in pressure drop and pumping power. Various thermal performance evaluation criteria, which take account of both heat transfer enhancement and pumping power, have been suggested for these enhanced performance surfaces based on different design constraints and objectives [1-6]. However, the criterion based on equal pumping power for the roughened and smooth surfaces suggested by Webb and Eckert [2] has been most widely used [7-41].

The performance ratios used by different researchers for the multitube heat exchangers are

$$
\begin{gathered}
R_{1}=\frac{\left(\mathrm{St} / \mathrm{St}_{s}\right)}{\left(f / f_{s}\right)^{1 / 3},} \\
R_{2}=\frac{q}{q_{s}}=\frac{h}{h_{s}},
\end{gathered}
$$

$$
R_{3}=\frac{\left(\mathrm{Nu} / \mathrm{Nu}_{s}\right)}{\left(f / f_{s}\right)^{1 / 3}}
$$

The Stanton number, St, Nusselt number, $\mathrm{Nu}$, and the friction factor, $f$, without subscript refer to the rough surface and with the subscript, $s$, refer to the smooth surface. The ratio of heat transfer coefficients for the rough and smooth surfaces, $h / h_{s}$, in (2) is replaced by the ratio of the overall heat transfer coefficients, $U / U_{s}$, when heat transfer between two fluids is considered. The heat transfer coefficient $h_{s}$ or $U_{s}$ in (2) is calculated at the Reynolds number $\mathrm{Re}_{s}$ for the smooth surfaced tubes, which is defined by

$$
\operatorname{Re}_{s}=\left(\frac{f}{f_{s}}\right)^{1 / 3} \operatorname{Re} .
$$

One of the old references where an equation similar to (1) has been given is that of Walker and Wilkie [1] for flow along the axis of a cluster of heated roughened rods in a smooth channel for the fixed mass flow rate and pumping power as constraints and the flow area as variable. Webb and Eckert [2], while discussing three different design objectives for multitube heat exchangers, proposed (1) for the design objective of enhanced heat transfer rate at equal pumping power for the roughened and smooth tubes. However, they 
developed this equation for a particular set of constraints and this equation is applicable only when a condition of specified ratio of mass velocities through the smooth and rough tubes is fulfilled. These constraints and conditions are discussed later. Many investigators [8-19], while using (1), did not take notice of the condition specified by Webb and Eckert [2] or Walker and Wilkie [1], and some of them [1119] have used the performance ratio $R_{1}$ for the square and rectangular ducts without mentioning the modification of the original constraints and condition specified for the multitube exchangers.

The performance ratio given by (2) has been suggested for enhanced surfaces by Bergles et al. [3] when the basic geometry of the exchanger is kept fixed and the mass flow rate is variable for fixed pumping power. These constraints are different from those specified by Webb and Eckert for (1). However, the researchers have, generally, regarded the two as equivalent.

When $\operatorname{Re}=\operatorname{Re}_{s}$ and $\operatorname{Pr}=\operatorname{Pr}_{s}, \mathrm{St} / \mathrm{St}_{s}=\mathrm{Nu} / \mathrm{Nu}_{s}$ and (1) will transform to (3). Such transformation is justified only when $\operatorname{Re}=\operatorname{Re}_{s}$ for the constraints and condition of (1), but some of the investigators while using (3) failed to satisfy this condition [20-30]. However, it is worth investigating whether such equation can be developed from fundamentals for design constraints different from those specified by Webb and Eckert for (1) and Bergles et al. for (2).

The performance ratios $R_{1}$ and $R_{3}$ have been presented in the form of plots of these ratios versus the relative mass velocity [2], the roughness parameters [8-10, 12], and the friction factor [10] and versus the roughness Reynolds number [11, 33]. A number of researchers [13-23, 25-31] have used Reynolds number as the abscissa parameter while Sara et al. [32] preferred $\mathrm{Re}_{s}$ as the abscissa parameter for the plots of performance ratios. Bergles et al. [3] advocate abscissa $\operatorname{Re}_{s}$ as a convenient reference for plot of ratio $R_{2}$ and the same has been used by Sethumadhavan and Raja Rao [34, 35]. However, such choice must be based on some logical ground and not on convenience.

For fixed geometry rectangular ducts, Liou and Hwang [36] presented the following performance ratio:

$$
R_{4}=\frac{\mathrm{Nu}}{\mathrm{Nu}_{s}^{*}},
$$

where $\mathrm{Nu}_{s}^{*}$ is the Nusselt number for the smooth duct at the Reynolds number $\operatorname{Re}_{s}$ defined by (4). The performance ratio $R_{4}$ has been plotted by researchers against parameter $f^{1 / 3} \mathrm{Re}$ [36-40]. However, Ichimiya [41] plotted $\mathrm{Nu} / \mathrm{Nu}_{s}$ versus the parameter $f^{1 / 3}$ Re.

Looking to the above discussion, the following objectives have been outlined for this paper: (i) to critically review the above-mentioned performance ratio equations, and to clearly restate and differentiate between the conditions and constraints for application of (1), (2), and (5); (ii) to specify the conditions and constraints for the application of (3); and (iii) to develop a performance ratio for the rectangular ducts when mass flow rate is kept fixed. To achieve the outlined objectives, the authors have thought that it is necessary to critically review the development of these equations from fundamentals, especially looking to the errors or omissions in application of different performance ratios.

For the development of the performance ratios in the present work, the fluid properties, and the temperature difference between the heat transferring surface and the bulk fluid have been assumed to be the same for both the rough and smooth surfaces. The error due to these assumptions is small for exchangers operating with low temperature differences. The analyses and results are based on the comparison of thermal performances of roughened and smooth channels of equal heat exchange surface area at equal pumping power.

\section{Performance Ratio for Multitube Heat Exchangers}

The relative heat transfer rate of the rough and smooth surfaces having surface areas $A$ and $A_{s}$, respectively, is given by Webb and Eckert [2] and Bergles et al. [3] as

$$
\frac{q}{q_{s}}=\frac{h A(\Delta T)}{[h A(\Delta T)]_{s}}
$$

where $\Delta T$ is the temperature difference between the heat transferring surface and bulk fluid.

In case of heat exchange between fluids on the two sides of a surface, the thermal resistance external to the surface under consideration (including scale, tube wall, and secondary fluid resistances) has been assumed to be the same for the rough and smooth heat exchangers.

In general, $\Delta T$ in (6) for the roughened surface will be somewhat smaller than the smooth surface due to the enhancement in the heat transfer coefficient. For equal values of temperature differences between heat transferring surface and bulk fluid for the rough and smooth surfaces, that is, $\Delta T=\Delta T_{s}$, as assumed by the previous investigators [2,3], the relative heat transfer rate equals the relative heat conductance, that is,

$$
\frac{K}{K_{s}}=\frac{(h A)}{\left(h_{s} A_{s}\right)} .
$$

Knowing that $h \propto \operatorname{St} G$, this equation transforms to

$$
\frac{K}{K_{s}}=\left(\frac{\mathrm{St}}{\mathrm{St}_{s}}\right)\left(\frac{A}{A_{s}}\right)\left(\frac{G}{G_{s}}\right),
$$

where $G$ is the mass velocity through a tube.

For a multitube heat exchanger with $N$ parallel tubes of diameter $D$ and length $L$, the mass flow rate $m=N(\pi / 4) D^{2} G$ and pressure drop $\Delta p=4 f L G^{2} /(2 \rho D)$. Using these relations the pumping power equation can be transformed as follows:

$$
P=\left(\frac{m}{\rho}\right) \Delta p=\frac{f(\pi D N L) G^{3}}{\left(2 \rho^{2}\right)} \propto f A G^{3},
$$

where $A(=\pi D N L)$ is the area of the surface exchanging heat. Hence, the relative pumping power relation for the rough and smooth surfaces, from (9), is

$$
\frac{P}{P_{s}}=\left(\frac{f}{f_{s}}\right)\left(\frac{A}{A_{s}}\right)\left(\frac{G}{G_{s}}\right)^{3} .
$$


The ratio of mass velocities for the smooth and rough tubes $\left(G_{s} / G\right)$ has been termed as relative mass velocity $G^{*}$ by Webb and Eckert [2]. Equations (8) and (10) in terms of $G^{*}$ are

$$
\begin{aligned}
& \frac{K}{K_{s}}=\left(\frac{\mathrm{St}}{\mathrm{St}_{s}}\right)\left(\frac{A}{A_{s}}\right)\left(\frac{1}{G^{*}}\right), \\
& \frac{P}{P_{s}}=\left(\frac{f}{f_{s}}\right)\left(\frac{A}{A_{s}}\right)\left(\frac{1}{G^{*}}\right)^{3} .
\end{aligned}
$$

For different constraints and mass flow rate conditions, the transformations of the above equations yield the equations of thermal performance evaluation as explained below.

Case (A): Flow Rate and Tube Diameter Fixed, Heat Exchanger Length, and Number of Tubes Variable. Webb and Eckert [2] gave a single expression for the performance evaluation based on the assumptions that the heat exchanger mass flow rate, $m$, and tube diameter, $D$, are held constant, and $G^{*}$ is changed by varying number of tubes. For flow through tubes, $G^{*}=\operatorname{Re}_{s} /$ Re.

Eliminating $G^{*}$ from (11) and (12), they arrived at the following relation:

$$
\frac{\left(K / K_{s}\right)}{\left[\left(P / P_{s}\right)^{1 / 3}\left(A / A_{s}\right)^{2 / 3}\right]}=\frac{\left(\mathrm{St} / \mathrm{St}_{s}\right)}{\left(f / f_{s}\right)^{1 / 3}} .
$$

For the constraints of equal pumping power and surface area, that is, $P / P_{s}=A / A_{s}=1$, Webb and Eckert transformed the above equation to

$$
\begin{aligned}
\frac{K}{K_{s}} & =\frac{\left(\mathrm{St} / \mathrm{St}_{s}\right)}{\left(f / f_{s}\right)^{1 / 3}} \\
\text { for } G_{s} & =\left(\frac{f}{f_{s}}\right)^{1 / 3} G .
\end{aligned}
$$

Equation (15) has been obtained from (12) and is the same as (4) when put in the terms of the Reynolds number. It means that the values of the Stanton number and friction factor for the smooth duct must be calculated at $\mathrm{Re}_{s}$ corresponding to $G_{s}$. To avoid the confusion, the present authors suggest that the smooth duct variables be written with asterisk $\left({ }^{*}\right)$ to indicate that their values are to be evaluated at different Reynolds numbers.

Webb and Eckert arrived at (14) with the assumption of $D_{s}=D$. Hence, the equal surface area constraint yields $N_{s} L_{s}=N L$. It implies that the length of the equivalent smooth surfaced exchanger will be $L_{s}=\left(N / N_{s}\right) L$.

Alternative Form of Equation for the Case (A). Equation (7) for the relative heat conductance can be written in terms of Nusselt number ratio as

$$
\frac{K}{K_{s}}=\left(\frac{\mathrm{Nu}}{\mathrm{Nu}_{s}}\right)\left(\frac{A}{A_{s}}\right)\left(\frac{D_{s}}{D}\right) .
$$

For the constraints of $D_{s}=D$ and $A_{s}=A$, this equation transforms to

$$
\frac{K}{K_{s}}=\frac{\mathrm{Nu}}{\mathrm{Nu}_{s}^{*}},
$$

where $\mathrm{Nu}_{s}^{*}$ refers to the smooth tube Nusselt number at the Reynolds number $\operatorname{Re}_{s}$ defined either by $G_{s} / G=\operatorname{Re}_{s} / \operatorname{Re}$ or (4). For $D_{s}=D$, the performance ratio given by (17) equals $h / h_{s}{ }^{*}$.

Case (B): Flow Rate and Heat Exchanger Length Fixed, Tube Diameter, and Number of Tubes Variable. If the constraints of Case (A) are modified to $m_{s}=m, L_{s}=L, A_{s}=A$, and $\operatorname{Re}_{s}=\mathrm{Re}$, the area and mass flow constraints give

$$
\begin{aligned}
& D_{s} N_{s}=D N, \\
& G_{s} D_{s}=G D .
\end{aligned}
$$

Combining these equations,

$$
G_{s}=G\left(\frac{N_{s}}{N}\right) \text {. }
$$

The performance ratio equation for this case will be

$$
\begin{gathered}
\frac{K}{K_{s}}=\frac{\left(\mathrm{St} / \mathrm{St}_{s}\right)}{\left(f / f_{s}\right)^{1 / 3}}, \\
\text { for } \frac{G_{s}}{G}=\frac{N_{s}}{N}=\frac{D}{D_{s}}=\left(\frac{f}{f_{s}}\right)^{1 / 3},
\end{gathered}
$$

that is, the number and diameter of the tubes are changed from $N$ to $N_{s}$ and from $D$ to $D_{s}$, respectively, to satisfy the condition of $N_{s} / N=\left(D / D_{s}\right)=G_{s} / G=\left(f / f_{s}\right)^{1 / 3}$.

For the given condition of $\mathrm{Re}_{s}=\mathrm{Re}$, the ratio St/St in (20) can be replaced by $\mathrm{Nu} / \mathrm{Nu}_{s}$, which will give the performance ratio of (3). Since $\left(f / f_{s}\right)^{1 / 3}=D / D_{s}$, the ratio $\left(\mathrm{Nu} / \mathrm{Nu}_{s}\right) /\left(f / f_{s}\right)^{1 / 3}$ of (3) equals $h / h_{s}$.

It must be noted that (20) of performance ratio is of the same form as (14), but the values of Stanton number and friction factor for the rough and smooth tubes in (20) are to be evaluated at the same Reynolds number.

Case (C): Basic Geometry Fixed and Flow Rate Variable. The performance ratio equation of Bergles et al. [3], given by (2), can be deduced from (7). They assumed a fixed geometry condition $\left(D_{s}=D, L_{s}=L, N_{s}=N\right)$, which gives $A_{s}=A$. Equation (4) is satisfied when mass velocity $G_{s}$ through the smooth tubes is greater than the mass velocity $G$ through the roughened tubes. Therefore, for the fixed geometry constraint, the mass flow rate for the smooth surfaced exchanger will be higher than the mass flow rate for the roughened one. The ratio $h / h_{s}^{*}$ can be replaced by $\mathrm{Nu} / \mathrm{Nu}_{s}^{*}$ since $D_{s}=D$.

\section{Performance Ratio for Rectangular Ducts}

The relative heat transfer rate equation in terms of the Nusselt number ratio, for this case, is

$$
\frac{q}{q_{s}}=\frac{K}{K_{s}}=\left(\frac{\mathrm{Nu}}{\mathrm{Nu}_{s}}\right)\left(\frac{A}{A_{s}}\right)\left(\frac{D_{h s}}{D_{h}}\right) .
$$

The pumping power equation for a rectangular duct of cross-section $(W \times H)$ can be transformed using mass 
flow rate, $m=G(W H)$, and hydraulic diameter, $D_{h}=$ $4 W H /[2(W+H)]:$

$$
\begin{aligned}
P & =\left(\frac{G W H}{\rho}\right)\left(\frac{4 f L G^{2}}{2 \rho}\right)\left[\frac{2(W+H)}{4 W H}\right] \\
& \propto f G^{3}[2 L(W+H)]=f\left(P^{\prime} L\right) G^{3},
\end{aligned}
$$

where $P^{\prime}$ is the perimeter of the duct.

The equal pumping power condition for the square or rectangular ducts can be achieved either by keeping duct geometry fixed and changing the mass flow rate or by keeping mass flow rate fixed and changing mass velocity by varying the duct cross-section.

Case (A): Basic Geometry Fixed and Flow Rate Variable. For the fixed geometry constraint of the duct, that is, $W_{s}=W$, $H_{s}=H$, and $L_{s}=L$,

$$
A_{s}=A, \quad D_{h s}=D_{h}, \quad \frac{G_{s}}{G}=\frac{\operatorname{Re}_{s}}{\operatorname{Re}} .
$$

Equation (22) will transform to

$$
\frac{q}{q_{s}}=\frac{\mathrm{Nu}}{\mathrm{Nu}_{s}^{*}},
$$

where $\mathrm{Nu}_{s}^{*}$ is the Nusselt number for the smooth duct at $\mathrm{Re}_{s}$ defined by (4), which is the condition of equal pumping power.

For a duct with heat transfer from all the four walls, the areas for heat transfer and pumping power equations will be equal. While for an asymmetrically heated duct, the two will have different values. However, for a fixed geometry duct, the above given results will be applicable without any change.

Case (B): High Aspect Ratio Duct and Flow Rate Fixed. When the mass flow rate, $m$, is fixed, the condition of equal pumping power can be achieved by increasing the mass velocity $G_{s}$ by decreasing the smooth duct cross-section or vice versa. For a duct of high aspect ratio $(W \gg H)$, whose width $W$ and length $L$ are fixed for the equal area constraint, hydraulic diameter $D_{h} \approx 2 \mathrm{H}$ and the Reynolds number can be expressed as

$$
\operatorname{Re} \approx \frac{2 m}{(W \mu)},
$$

that is, $\operatorname{Re}=\operatorname{Re}_{s}$ if mass flow rate, $m$, and duct width, $W$, are fixed.

The pumping power equation for this case will be

$$
P \approx \frac{f(W L) G^{3}}{\rho^{2}}
$$

Thus, the condition of equal pumping power is achieved by increasing the mass velocity $G_{s}$ in the smooth duct to satisfy the condition $G_{s}=G\left(f / f_{s}\right)^{1 / 3}$. This can be affected by decreasing the height of the smooth duct to $H_{s}=m /\left(G_{s} W\right)$. Hence, for $m=m_{s}, H_{s} G_{s}=H G$. The performance ratio will be given by the heat transfer enhancement ratio, that is,

$$
\frac{q}{q_{s}}=\frac{h}{h_{s}} .
$$

Equation (28) can be transformed by using the relations $h=\mathrm{Nuk} / D_{h} \approx \mathrm{Nuk} /(2 H)$ for high aspect ratio ducts and $H_{s} G_{s}=H G$ :

$$
\begin{aligned}
\frac{h}{h_{s}} & =\frac{[\mathrm{Nu} k /(2 H)]}{\left[\mathrm{Nu}_{s} k /\left(2 H_{s}\right)\right]} \\
& =\frac{\left(\mathrm{Nu} / \mathrm{Nu}_{s}\right)}{\left(H / H_{s}\right)} \\
& =\frac{\left(\mathrm{Nu} / \mathrm{Nu}_{s}\right)}{\left(G_{s} / G\right)} \\
& =\frac{\left(\mathrm{Nu} / \mathrm{Nu}_{s}\right)}{\left(f / f_{s}\right)^{1 / 3}} \\
& =\frac{\left(\mathrm{St} / \mathrm{St}_{s}\right)}{\left(f / f_{s}\right)^{1 / 3}} \quad \text { for } \mathrm{Re}=\mathrm{Re}_{s} .
\end{aligned}
$$

For the duct with heat transfer from all the four walls, the surface area $A=2(W+L) \approx 2 W L$, and for an asymmetrically heated duct (with broader wall heated), $A=W L$.

The boundary condition of asymmetric heating of a high aspect ratio duct is encountered in solar air heaters. Gas turbine blade cooling channels are modeled as rectangular ducts of various aspect ratios with heat flux at all the four walls.

\section{Presentation of Results}

Various performance ratio equations discussed and developed in this paper have been listed in Table 1 along with the constraints and the conditions to be fulfilled. All the geometric and flow parameters have been fully defined.

Basically, all the tabulated performance ratios are heat transfer enhancement ratios. They are of two forms: either $h / h_{s}$ when $D_{h s}$ (or $\left.D\right) \neq D_{h}$ (or $\left.D\right)$ or $h / h_{s}^{*}\left(=\mathrm{Nu} / \mathrm{Nu}_{s}^{*}\right)$ when $D_{h s}($ or $D)=D_{h}($ or $D)$. However, the ratio $U / U_{s}^{*}$ for heat transfer between two fluids cannot be replaced by $\mathrm{Nu} / \mathrm{Nu}_{s}^{*}$. It is to note that the choice of the performance ratio depends on the constraints of the application. It is also desirable that an investigator using any of the performance ratio equations should explicitly mention the design constraints associated with that equation and also the conditions to be fulfilled.

For the two out of the six performance ratios given in Table 1, the Reynolds numbers for the rough and smooth surfaces are equal, that is, $\mathrm{Re}=\mathrm{Re}_{s}$. Therefore, $\mathrm{Re}$ or $\mathrm{Re}_{s}$ is a logical parameter for the plots of the performance results when these criteria are used. For the remaining four performance ratios, values of the Stanton number and friction factor for the roughened and smooth surfaces are calculated at different Reynolds numbers. Further, the roughness parameters, such as the relative roughness height, pitch, and orientation of the roughness elements with respect to the flow, are not having any meaning for a smooth surface. Therefore, neither the Reynolds number nor the roughness parameters can be the logical abscissa parameter for presentation of the performance of the roughened surfaces versus a smooth surface when these four criteria are applied. In these cases, 
TABLE 1: Performance ratio equations.

\begin{tabular}{|c|c|c|c|}
\hline Investigators & Performance ratio & Constraints & Conditions to be fulfilled \\
\hline \multicolumn{4}{|c|}{ Multi-tube Exchangers } \\
\hline Webb and Eckert [2] & $\left(\mathrm{St} / \mathrm{St}_{s}^{*}\right) /\left(f / f_{s}^{*}\right)^{1 / 3}$ & $\begin{array}{c}m_{s}=m, D_{s}=D, \text { and } A_{s}=A, \\
N_{s} \neq N, \text { and } L_{s} \neq L\end{array}$ & $\begin{array}{c}G_{s}>G, L_{s}>L, N_{s}<N, \\
L_{s}=\left(N / N_{s}\right) L \\
G_{s} / G=N / N_{s}=\operatorname{Re}_{s} / \operatorname{Re}=\left(f / f_{s}\right)^{1 / 3}, \\
\operatorname{Re}_{s}=\left(f / f_{s}^{*}\right)^{1 / 3} \operatorname{Re}\end{array}$ \\
\hline Present authors & $\mathrm{Nu} / \mathrm{Nu}_{s}^{*}\left(=h / h_{s}^{*}\right)$ & $\begin{array}{c}m_{s}=m, D_{s}=D, \text { and } A_{s}=A, \\
N_{s} \neq N, \text { and } L_{s} \neq L\end{array}$ & $\begin{array}{c}G_{s}>G, L_{s}>L, N_{s}<N, \\
L_{s}=\left(N / N_{s}\right) L, \\
G_{s} / G=N / N_{s}=\operatorname{Re}_{s} / \operatorname{Re}=\left(f / f_{s}\right)^{1 / 3}, \\
\operatorname{Re}_{s}=\left(f / f_{s}^{*}\right)^{1 / 3} \operatorname{Re}\end{array}$ \\
\hline Present authors & $\begin{array}{c}\left(\mathrm{St} / \mathrm{St}_{s}\right) /\left(f / f_{s}\right)^{1 / 3} \\
\left(\mathrm{Nu} / \mathrm{Nu}_{s}\right) /\left(f / f_{s}\right)^{1 / 3} \\
\quad \text { or } h / h_{s}\end{array}$ & $\begin{array}{c}m_{s}=m, L_{s}=L, A_{s}=A, \text { and } \\
\operatorname{Re}_{s}=\operatorname{Re}, D_{s} \neq D, N_{s} \neq N\end{array}$ & $\begin{array}{c}G_{s}>G, D_{s}<D, N_{s}>N \\
G_{s} / G=\left(f / f_{s}\right)^{1 / 3}=N_{s} / N=D / D_{s}\end{array}$ \\
\hline Bergles et al. [3] & $\begin{array}{c}h / h_{s}^{*} \text { or } U / U_{s}^{*} \\
\left(h / h_{s}^{*}=\mathrm{Nu} / \mathrm{Nu}_{s}^{*}\right)\end{array}$ & $\begin{array}{c}D_{s}=D, L_{s}=L, N_{s}=N \text {, and } \\
A_{s}=A, m_{s} \neq m\end{array}$ & $\begin{array}{c}m_{s}>m, G_{s}>G, \\
G_{s} / G=\operatorname{Re}_{s} / \operatorname{Re}, \\
\operatorname{Re}_{s}=\left(f / f_{s}^{*}\right)^{1 / 3} \operatorname{Re}\end{array}$ \\
\hline \multicolumn{4}{|c|}{ Rectangular Duct } \\
\hline Liou and Hwang [36] & $\mathrm{Nu} / \mathrm{Nu}_{s}^{*}=h / h_{s}^{*}$ & $\begin{array}{c}m_{s} \neq m, W_{s}=W, H_{s}=H \\
L_{s}=L, \text { and } A_{s}=A\end{array}$ & $\begin{array}{c}m_{s}>m, G_{s}>G \\
G_{s} / G=\operatorname{Re}_{s} / \operatorname{Re} \\
\operatorname{Re}_{s}=\left(f / f_{s}^{*}\right)^{1 / 3} \operatorname{Re}\end{array}$ \\
\hline Present authors & $\begin{array}{c}h / h_{s} \\
\left(\mathrm{Nu} / \mathrm{Nu}_{s}\right) /\left(f / f_{s}\right)^{1 / 3} \\
\text { or }\left(\mathrm{St}_{\mathrm{St}}\right) /\left(f / f_{s}\right)^{1 / 3}\end{array}$ & $\begin{array}{c}\text { High aspect ratio duct } \\
(W \gg H): W_{s}=W, L_{s}=L, \\
H_{s} \neq H, \text { and } m_{s}=m\end{array}$ & $\begin{array}{c}G_{s}>G, H_{s}<H, H_{s} G_{s}=H G \\
G_{s}=G\left(f / f_{s}\right)^{1 / 3} \\
\operatorname{Re}=\operatorname{Re}_{s} \approx 2 m /(W \mu)\end{array}$ \\
\hline
\end{tabular}

* The parameters with asterisk $\left({ }^{*}\right)$ are to be evaluated at the Reynolds number $\operatorname{Re}_{s}$ defined in column 4 .

the common parameter for the smooth and rough surfaces is $\left(f_{s}^{* 1 / 3} \operatorname{Re}_{s}\right)$ or $\left(f^{1 / 3} \mathrm{Re}\right)$. Some researchers have used this abscissa parameter for enhanced performance rectangular ducts as mentioned earlier.

It must be noted that the value of the friction factor $f_{s}^{*}$ for the smooth channel in the equation $\operatorname{Re}_{s}=\left[\operatorname{Re}\left(f / f_{s}^{*}\right)^{1 / 3}\right]$ corresponds to the Reynolds number $\operatorname{Re}_{s}$ and, therefore, this equation must be converted to an explicit form by substitution of friction correlation of smooth duct and rearranging the terms. In case of a heat exchanger with heat transfer between two fluids, the present criteria represent upper limits to heat transfer enhancement [3]. Once the preferred type of roughness is selected, the thermal resistances external to the enhanced surface and effects of variable fluid properties may be considered.

4.1. Application to Solar Air Heater Ducts with Roughened Absorber Plate. In order to illustrate the application of the performance evaluation criteria presented above for high aspect ratio rectangular ducts with asymmetric heating, data from an earlier experimental study of the first author [42] have been used. The flow and thermal boundary conditions of the roughened duct of their study correspond closely to those of solar air heater ducts. The discrete and discontinuous repeated rectangular cross-section rib roughness arrangements employed in the study are shown in Figure 1. The ribs have been arranged in both $\mathrm{v}$-up and v-down patterns. They compared the thermal performance of different rib arrangements based on equal pumping power for roughened and smooth ducts using performance parameter $\mathrm{Nu} / \mathrm{Nu}_{s}{ }^{*}$ defined by (25) and presented the performance plots of this parameter versus the parameter $f^{1 / 3}$ Re as shown in Figure 2. The constraints and conditions for the application of this criterion, as detailed in Table 1, are basically fixed geometry and reduced flow rate for the roughened ducts. It is an appropriate criterion when the smooth surfaced absorber plate of an existing solar air heater is replaced by a roughened absorber plate.

Alternatively, the thermal performance at equal pumping power has been presented in Figure 3 as plots of $\left(\mathrm{Nu} / \mathrm{Nu}_{s}\right) /\left(f / f_{s}\right)^{1 / 3}\left[\right.$ or $\left.\left(\mathrm{St} / \mathrm{St}_{s}\right) /\left(f / f_{s}\right)^{1 / 3}\right]$ versus the Reynolds number. The basic conditions and constraints, as outlined in Table 1, are those of equal mass flow rates for smooth and roughened ducts and an increased height of the roughened duct as compared to the smooth duct.

It is interesting to note that the ordinate values of the above discussed performance plots and hence the conclusion drawn from these plots regarding the selection of the preferred roughness type are the same. But the first criterion specifies the operational condition of reduced flow rate for the existing solar air heater when the smooth surfaced absorber plate is replaced by a roughened one, while the second criterion gives design recommendation of increased duct height for the roughened duct solar air heater.

\section{Conclusions}

Various existing equations for the thermal performance evaluation at equal pumping power for the roughened and 


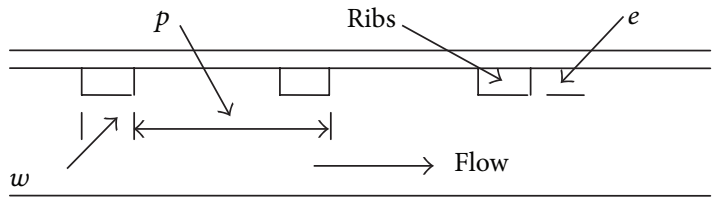

Rib geometry

(a)

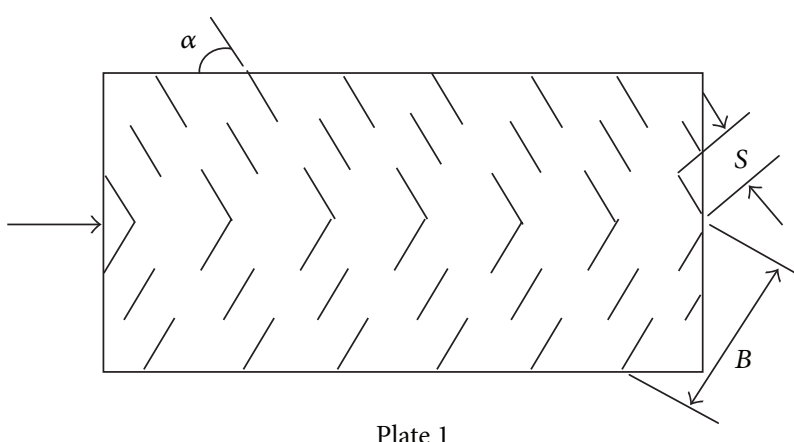

Plate 1

$\left(60^{\circ}\right.$ v-down discrete, $\left.B / S=3\right)$

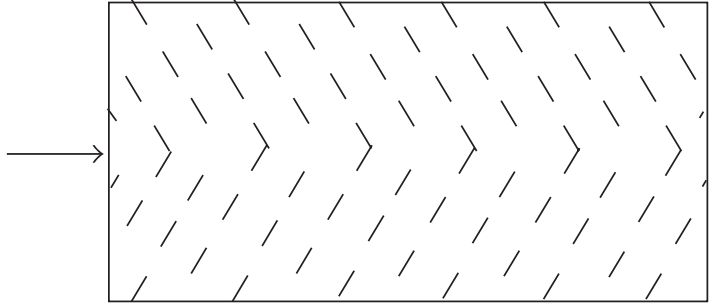

Plate 2

$\left(60^{\circ} \mathrm{v}\right.$-down discrete, $\left.B / S=6\right)$

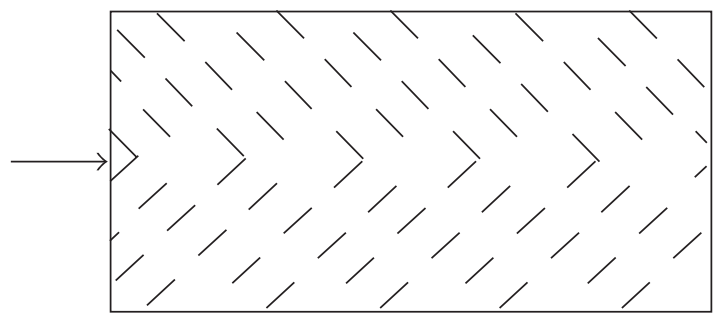

Plate 4

$\left(45^{\circ} \mathrm{v}\right.$-down discrete, $\left.B / S=6\right)$

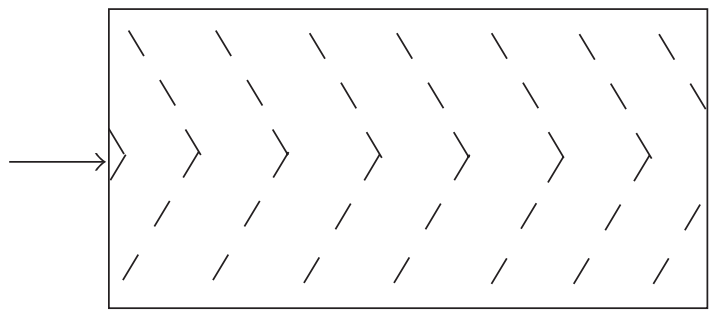

Plate 6

$\left(60^{\circ} \mathrm{v}\right.$-down discontinuous, $\left.B / S=6\right)$

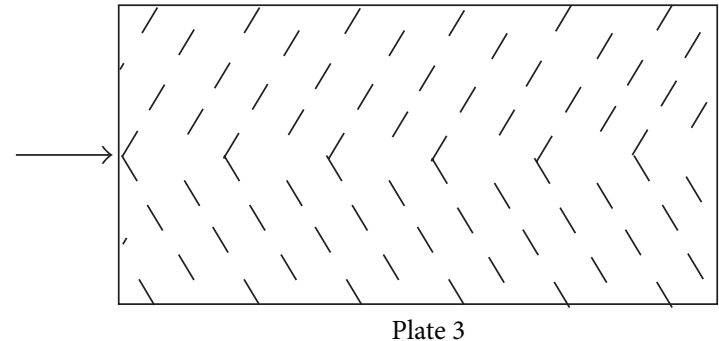

$\left(60^{\circ}\right.$ v-up discrete, $\left.B / S=6\right)$

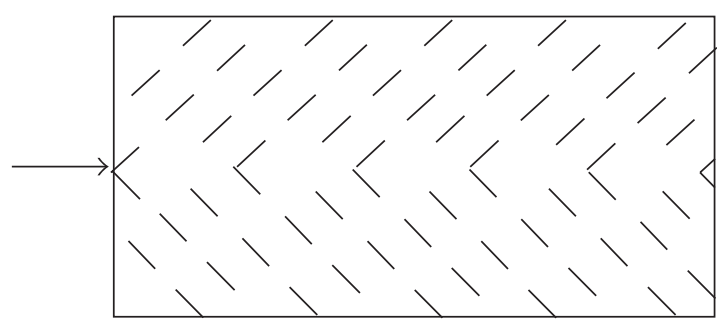

Plate 5

$\left(45^{\circ}\right.$ v-up discrete, $B / S=6$ )

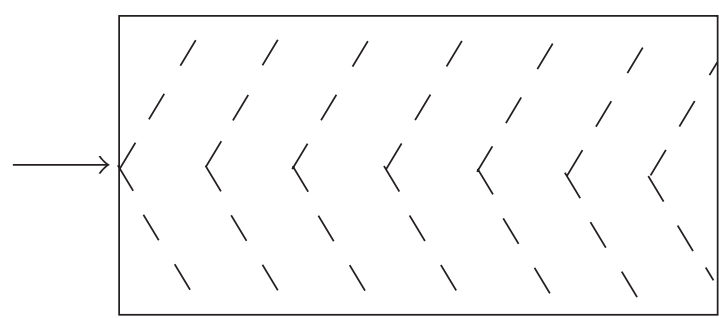

Plate 7

(60 v-up discontinuous, $B / S=6$ )

(b)

Figure 1: (a) Longitudinal section of the rectangular duct with $60^{\circ} \mathrm{v}$-down discrete rib roughness $\left(e / D_{h}=0.0469, p / e=10.63, w / e=2.06\right)$. (b) Rib arrangements [42].

smooth surfaced multitube and rectangular duct heat exchangers (such as solar air heater and gas turbine blade cooling channels) have been critically reviewed. The design constraints and conditions for their application have been explicitly stated. Two new performance ratio equations have been developed for the constraints not covered earlier. Finally the logical abscissa parameters for the plots of performance evaluation results have been suggested. 


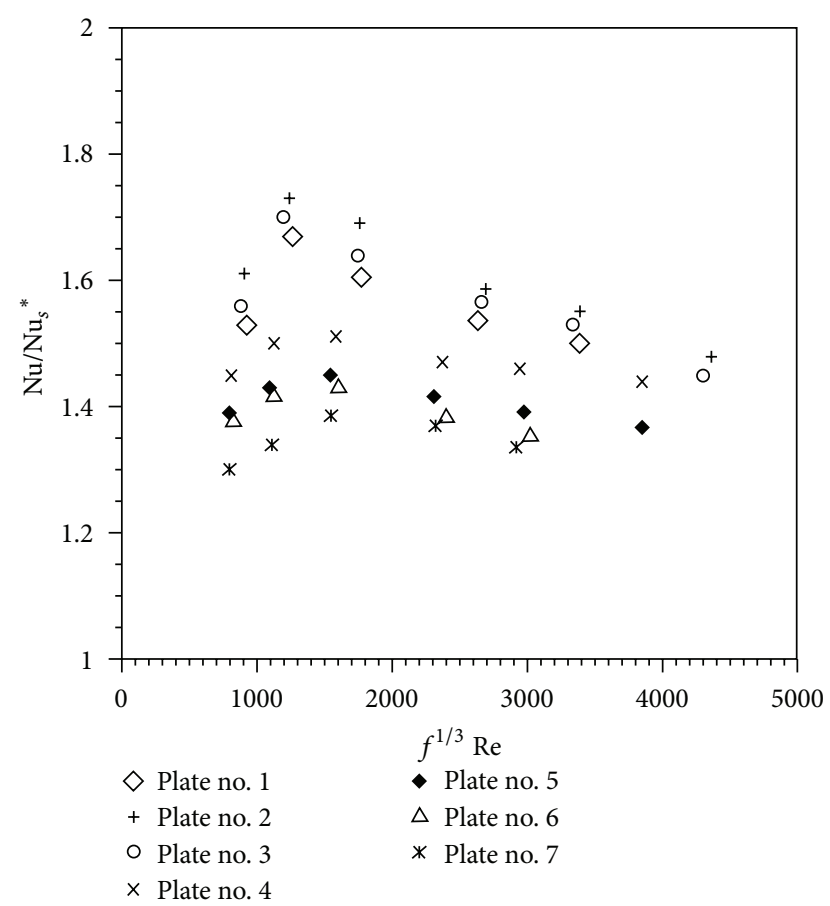

FIgURE 2: Thermal performance at equal pumping power; Basic geometry fixed, $G_{s} / G=\operatorname{Re}_{s} / \operatorname{Re}=\left(f / f_{s}^{*}\right)^{1 / 3}[42]$.

\section{Nomenclature}

$A$ : $\quad$ Heat transfer surface area $\left[\mathrm{m}^{2}\right]$

$B / S$ : Relative roughness length of discrete ribs [-]

$c_{p}: \quad$ Specific heat of air $\left[\mathrm{Jkg}^{-1} \mathrm{~K}^{-1}\right]$

D: $\quad$ Pipe inside diameter $[\mathrm{m}]$

$D_{h}: \quad$ Hydraulic diameter of duct $=4 W H /[2(W+H)][\mathrm{m}]$

$e: \quad$ Rib height $[\mathrm{m}]$

$e / D_{h}$ : Relative roughness height $[-]$

$f$ : $\quad$ Fanning friction factor $[-]$

$G$ : $\quad$ Mass velocity $\left[\mathrm{kgs}^{-1} \mathrm{~m}^{-2}\right]$

$G^{*}: \quad$ Relative mass velocity $=G_{s} / G[-]$

$h$ : Heat transfer coefficient $\left[\mathrm{Wm}^{-2} \mathrm{~K}^{-1}\right]$

$H$ : $\quad$ Duct height $[\mathrm{m}]$

$k$ : Thermal conductivity of fluid $\left[\mathrm{Wm}^{-1} \mathrm{~K}^{-1}\right]$

$K: \quad$ Overall heat conductance $=h A\left[\mathrm{WK}^{-1}\right]$

$L: \quad$ Length of the flow passage $[\mathrm{m}]$

$m$ : Mass flow rate $[\mathrm{kg} / \mathrm{s}]$

$N$ : Number of parallel tubes in flow passage [-]

$\mathrm{Nu}$ : Nusselt number [-]

$p: \quad$ Rib pitch $[\mathrm{m}]$

$P$ : $\quad$ Pumping power [W]

$P^{\prime}$ : $\quad$ Perimeter of rectangular section duct [m]

Pr: $\quad$ Prandtl number [-]

p/e: Relative roughness pitch $[-]$

$q$ : Heat transfer rate [W]

Re: Reynolds number, $D G / \mu$ or $D_{h} G / \mu[-]$

St: $\quad$ Stanton number, $h /\left(G c_{p}\right)[-]$

$\Delta T: \quad$ Temperature difference $\left[{ }^{\circ} \mathrm{C}\right]$

$U: \quad$ Overall heat transfer coefficient $\left[\mathrm{Wm}^{-2} \mathrm{~K}^{-1}\right]$

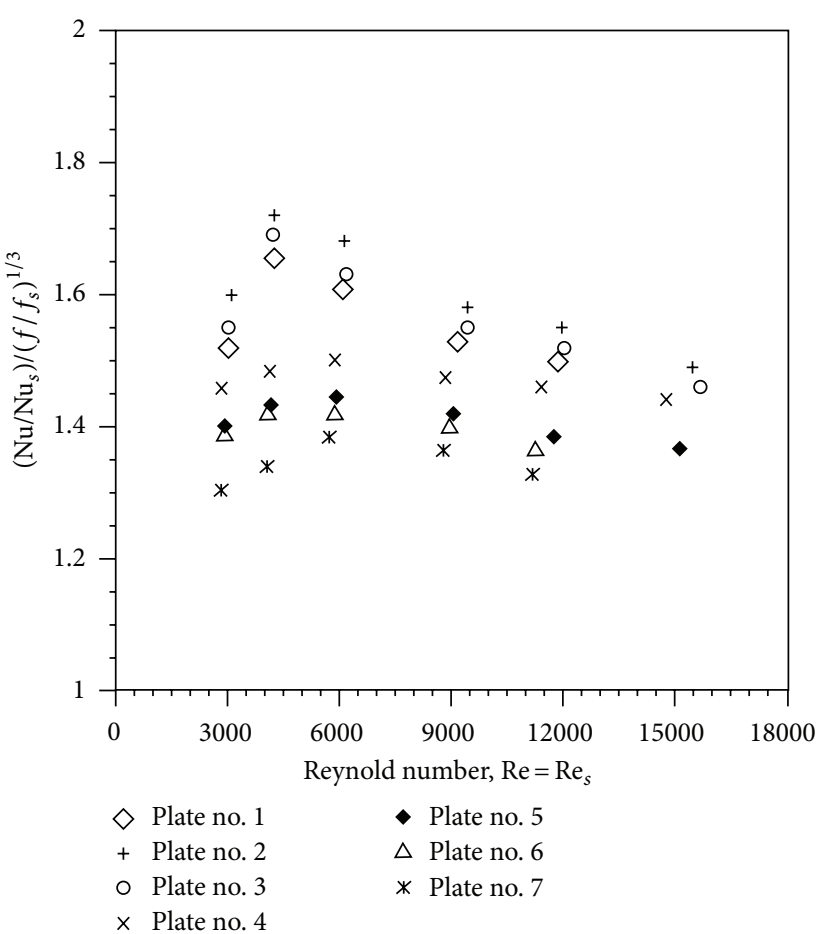

FIGURE 3: Thermal performance at equal pumping power; Flow rate fixed $\left(m=m_{s}\right), H_{s} / H=G / G_{s}=\left(f_{s} / f\right)^{1 / 3}$.

$w$ : Width of rib $[\mathrm{m}]$

$W$ : Width of the duct $[\mathrm{m}]$.

Greek Symbols

$\Delta p$ : Pressure drop $[\mathrm{Pa}]$

$\mu: \quad$ Viscosity of fluid $[\mathrm{Pa} \mathrm{s}]$

$\rho: \quad$ Density of fluid $\left[\mathrm{kg} / \mathrm{m}^{3}\right]$.

Subscript

$s$ : Smooth surfaceunsubscripted variables refer to rough surfaces.

\section{References}

[1] V. Walker and D. Wilkie, "The wider application of roughened heat transfer surfaces as developed for advanced gas-cooled reactors," in Proceedings of Symposium on High Pressure Gas as a Heat Transfer Medium, London, UK, 1967, paper no. 26.

[2] R. L. Webb and E. R. G. Eckert, "Application of rough surfaces to heat exchanger design," International Journal of Heat and Mass Transfer, vol. 15, no. 9, pp. 1647-1658, 1972.

[3] A. E. Bergles, A. R. Blumenkrantz, and J. Taborek, "Performance evaluation criteria for enhanced heat transfer surfaces," in Proceedings of the 5th International Heat Transfer Conference, vol. 2, pp. 239-243, Tokyo, Japan, 1974.

[4] K. W. Boer, "Payback of solar systems," Solar Energy, vol. 20, pp. 225-232, 1978 .

[5] K. Altfeld, W. Leiner, and M. Fiebig, "Second law optimization of flat-plate solar air heaters-part I: the concept of net exergy 
flow and the modeling of solar air heaters," Solar Energy, vol. 41, no. 2, pp. 127-132, 1988.

[6] A. Cortés and R. Piacentini, "Improvement of the efficiency of a bare solar collector by means of turbulence promoters," Applied Energy, vol. 36, no. 4, pp. 253-261, 1990.

[7] W. J. White and L. White, "The effect of rib profile on heat transfer and pressure loss properties of transversely ribbed roughened surfaces," in Augmentation of Heat Transfer, A. E. Bergles and R. L. Webb, Eds., pp. 44-54, ASME, New York, USA, 1970.

[8] F. Williams, M. A. M. Pirie, and C. Warburton, "Heat transfer from surfaces roughened by ribs," in Augmentation of Heat Transfer, A. E. Bergles and R. L. Webb, Eds., pp. 36-43, ASME, New York, USA, 1970.

[9] F. Williams and J. Watts, "The development of rough surfaces with improved heat transfer performance and a study of the mechanisms involved," in Proceedings of 4th International Heat Transfer Conference, vol. 2, pp. 1-11, Paris, France, 1970.

[10] M. J. Lewis, "Optimising the thermohydraulic performance of rough surfaces," International Journal of Heat and Mass Transfer, vol. 18, no. 11, pp. 1243-1248, 1975.

[11] J. C. Han, J. S. Park, and C. K. Lei, "Heat transfer enhancement in channels with turbulence promoters," Journal of Engineering for Gas Turbines and Power, vol. 107, pp. 628-635, 1985.

[12] J. C. Han and J. S. Park, "Developing heat transfer in rectangular channels with rib turbulators," International Journal of Heat and Mass Transfer, vol. 31, no. 1, pp. 183-195, 1988.

[13] S. C. Lau, R. T. Kukreja, and R. D. Mcmillin, "Effects of Vshaped rib arrays on turbulent heat transfer and friction of fully developed flow in a square channel," International Journal of Heat and Mass Transfer, vol. 34, no. 7, pp. 1605-1616, 1991.

[14] S. C. Lau, R. D. McMillin, and J. C. Han, “Turbulent heat transfer and friction in a square channel with discrete rib turbulators," Journal of Turbomachinery, vol. 113, no. 3, pp. 360-366, 1991.

[15] K. B. Muluwork, S. C. Solanki, and J. S. Saini, "Study of heat transfer and friction in solar air heaters roughened with staggered discrete ribs," in Proceedings of 4th ISHMT-ASME Heat and Mass Transfer Conference and 15th Heat and Mass Transfer Conference, pp. 391-398, IAT, Pune, India, 2000.

[16] A. E. Momin, J. S. Saini, and S. C. Solanki, "Heat transfer and friction in solar air heater duct with V-shaped rib roughness on absorber plate," International Journal of Heat and Mass Transfer, vol. 45, no. 16, pp. 3383-3396, 2002.

[17] S. V. Karmare and A. N. Tikekar, "Heat transfer and friction factor correlation for artificially roughened duct with metal grit ribs," International Journal of Heat and Mass Transfer, vol. 50, no. 21-22, pp. 4342-4351, 2007.

[18] K. R. Aharwal, B. K. Gandhi, and J. S. Saini, "Experimental investigation on heat-transfer enhancement due to a gap in an inclined continuous rib arrangement in a rectangular duct of solar air heater," Renewable Energy, vol. 33, no. 4, pp. 585-596, 2008.

[19] S. B. Bopche and M. S. Tandale, "Experimental investigations on heat transfer and frictional characteristics of a turbulator roughened solar air heater duct," International Journal of Heat and Mass Transfer, vol. 52, no. 11-12, pp. 2834-2848, 2009.

[20] M. E. Taslim, T. Li, and D. M. Kercher, "Experimental heat transfer and friction in channels roughened with angled, Vshaped, and discrete ribs on two opposite walls," Journal of Turbomachinery, vol. 118, no. 1, pp. 20-28, 1996.
[21] S. W. Ahn, "The effects of roughness types on friction factors and heat transfer in roughened rectangular duct," International Communications in Heat and Mass Transfer, vol. 28, no. 7, pp. 933-942, 2001.

[22] X. Gao and B. Sundén, "Heat transfer and pressure drop measurements in rib-roughened rectangular ducts," Experimental Thermal and Fluid Science, vol. 24, no. 1-2, pp. 25-34, 2001.

[23] L. Wang and B. Sunden, "Performance comparison of some tube inserts," International Communication of Heat and Mass Transfer, vol. 29, no. 1, pp. 45-56, 2002.

[24] S. W. Moon and S. C. Lau, "Heat transfer between blockages with holes in a rectangular channel," Journal of Heat Transfer, vol. 125, no. 4, pp. 587-594, 2003.

[25] L. Wang and B. Sunden, "Experimental investigation of local heat transfer in a square duct with various-shaped ribs," Heat and Mass Transfer, vol. 43, no. 8, pp. 759-766, 2007.

[26] P. Promvonge and C. Thianpong, "Thermal performance assessment of turbulent channel flows over different shaped ribs," International Communications in Heat and Mass Transfer, vol. 35, no. 10, pp. 1327-1334, 2008.

[27] A. Layek, J. S. Saini, and S. C. Solanki, "Effect of chamfering on heat transfer and friction characteristics of solar air heater having absorber plate roughened with compound turbulators," Renewable Energy, vol. 34, no. 5, pp. 1292-1298, 2009.

[28] K. R. Aharwal, B. K. Gandhi, and J. S. Saini, "Heat transfer and friction characteristics of solar air heater ducts having integral inclined discrete ribs on absorber plate," International Journal of Heat and Mass Transfer, vol. 52, no. 25-26, pp. 5970-5977, 2009.

[29] A. Lanjewar, J. L. Bhagoria, and R. M. Sarviya, "Experimental study of augmented heat transfer and friction in solar air heater with different orientations of W-Rib roughness," Experimental Thermal and Fluid Science, vol. 35, no. 6, pp. 986-995, 2011.

[30] S. Singh, S. Chander, and J. S. Saini, "Investigations on thermohydraulic performance due to flow-attack-angle in $\mathrm{V}$-down rib with gap in a rectangular duct of solar air heater," Applied Energy, vol. 97, pp. 907-912, 2012.

[31] K. Ko and N. K. Anand, "Use of porous baffles to enhance heat transfer in a rectangular channel," International Journal of Heat and Mass Transfer, vol. 46, no. 22, pp. 4191-4199, 2003.

[32] O. N. Sara, T. Pekdemir, S. Yapici, and M. Yilmaz, "Heat-transfer enhancement in a channel flow with perforated rectangular blocks," International Journal of Heat and Fluid Flow, vol. 22, no. 5, pp. 509-518, 2001.

[33] D. L. Gee and R. L. Webb, "Forced convection heat transfer in helically rib-roughened tubes," International Journal of Heat and Mass Transfer, vol. 23, no. 8, pp. 1127-1136, 1980.

[34] R. Sethumadhavan and M. Raja Rao, "Turbulent flow heat transfer and fluid friction in helical-wire-coil-inserted tubes," International Journal of Heat and Mass Transfer, vol. 26, no. 12, pp. 1833-1845, 1983.

[35] R. Sethumadhavan and M. Raja Rao, "Turbulent flow friction and heat transfer characteristics of single- and multistart spirally enhanced tubes," Journal of Heat Transfer, vol. 108, no. 1, pp. 55-61, 1986.

[36] T.-M. Liou and J.-J. Hwang, "Effect of ridge shapes on turbulent heat transfer and friction in a rectangular channel," International Journal of Heat and Mass Transfer, vol. 36, no. 4, pp. 931940, 1993.

[37] J.-J. Hwang and T.-M. Liou, "Augmented heat transfer in a rectangular channel with permeable ribs mounted on the wall," Journal of Heat Transfer, vol. 116, no. 4, pp. 912-920, 1994. 
[38] T.-M. Liou, W. B. Wang, and Y. J. Chang, "Holographic interferometry study of spatially periodic heat transfer in a channel with ribs detached from one wall," Journal of Heat Transfer, vol. 117, no. 1, pp. 32-39, 1995.

[39] J.-J. Hwang, T. Y. Lia, and T.-M. Liou, "Effect of fence thickness on pressure drop and heat transfer in a perforated-fenced channel," International Journal of Heat and Mass Transfer, vol. 41, no. 4-5, pp. 811-816, 1998.

[40] R. Karwa, "Experimental studies of augmented heat transfer and friction in asymmetrically heated rectabgular ducts with ribs on the heated wall in transverse, inclined, v-continous and v-discrete pattern," International Communications in Heat and Mass Transfer, vol. 30, no. 2, pp. 241-250, 2003.

[41] K. Ichimiya, "Effects of several roughness elements on an insulated wall for heat transfer from the opposite smooth heated surface in a parallel plate duct," Journal of Heat Transfer, vol.109, no. 1, pp. 68-73, 1987.

[42] R. Karwa, R. D. Bairwa, B. P. Jain, and N. Karwa, "Experimental study of the effects of rib angle and discretization on heat transfer and friction in an asymmetrically heated rectangular duct," Journal of Enhanced Heat Transfer, vol. 12, no. 4, pp. 343355, 2005. 


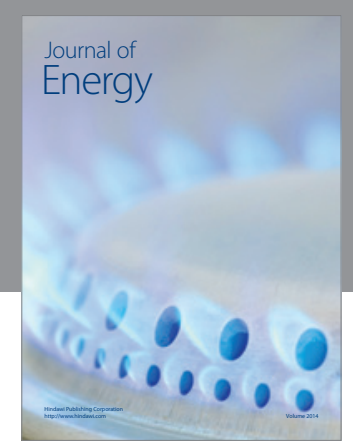

Journal of

Industrial Engineering
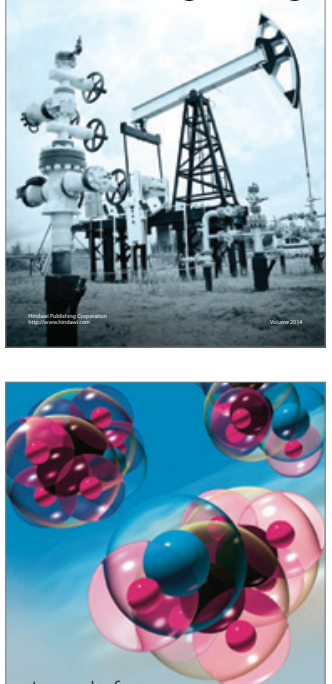

Fuels
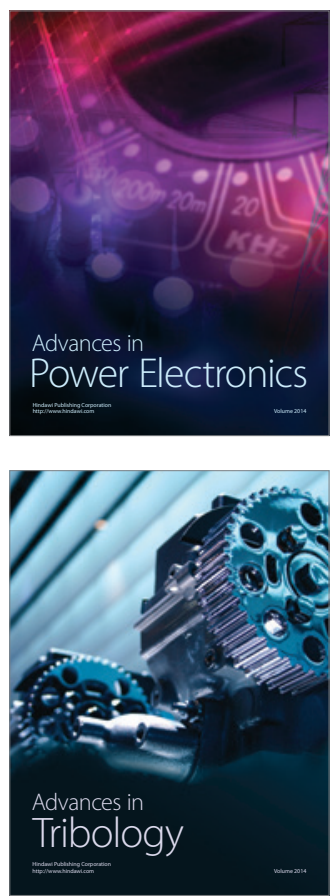

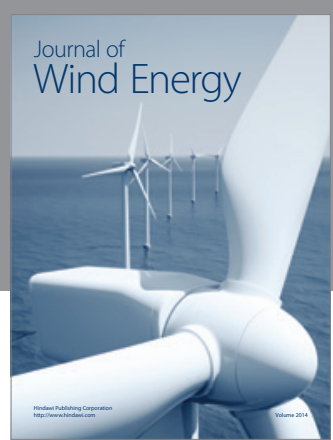

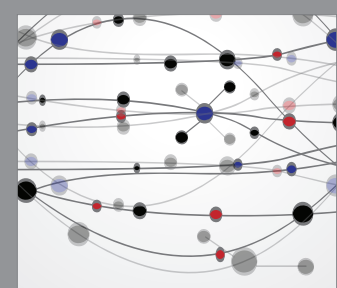

The Scientific World Journal

Submit your manuscripts at http://www.hindawi.com

Journal of

Structures
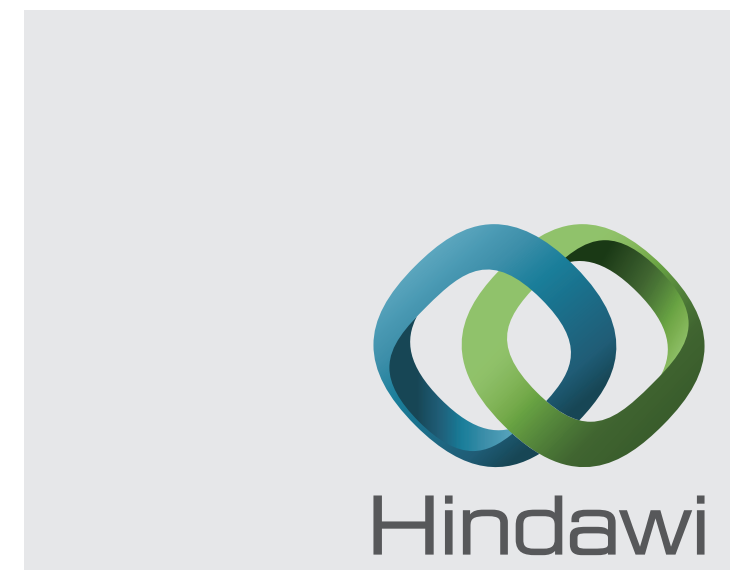

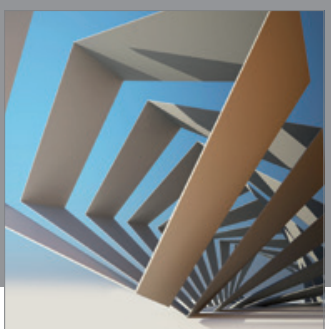

Rotating

Machinery
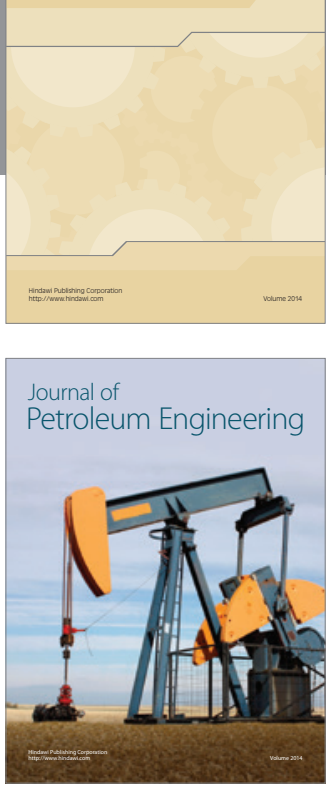

Journal of

Solar Energy
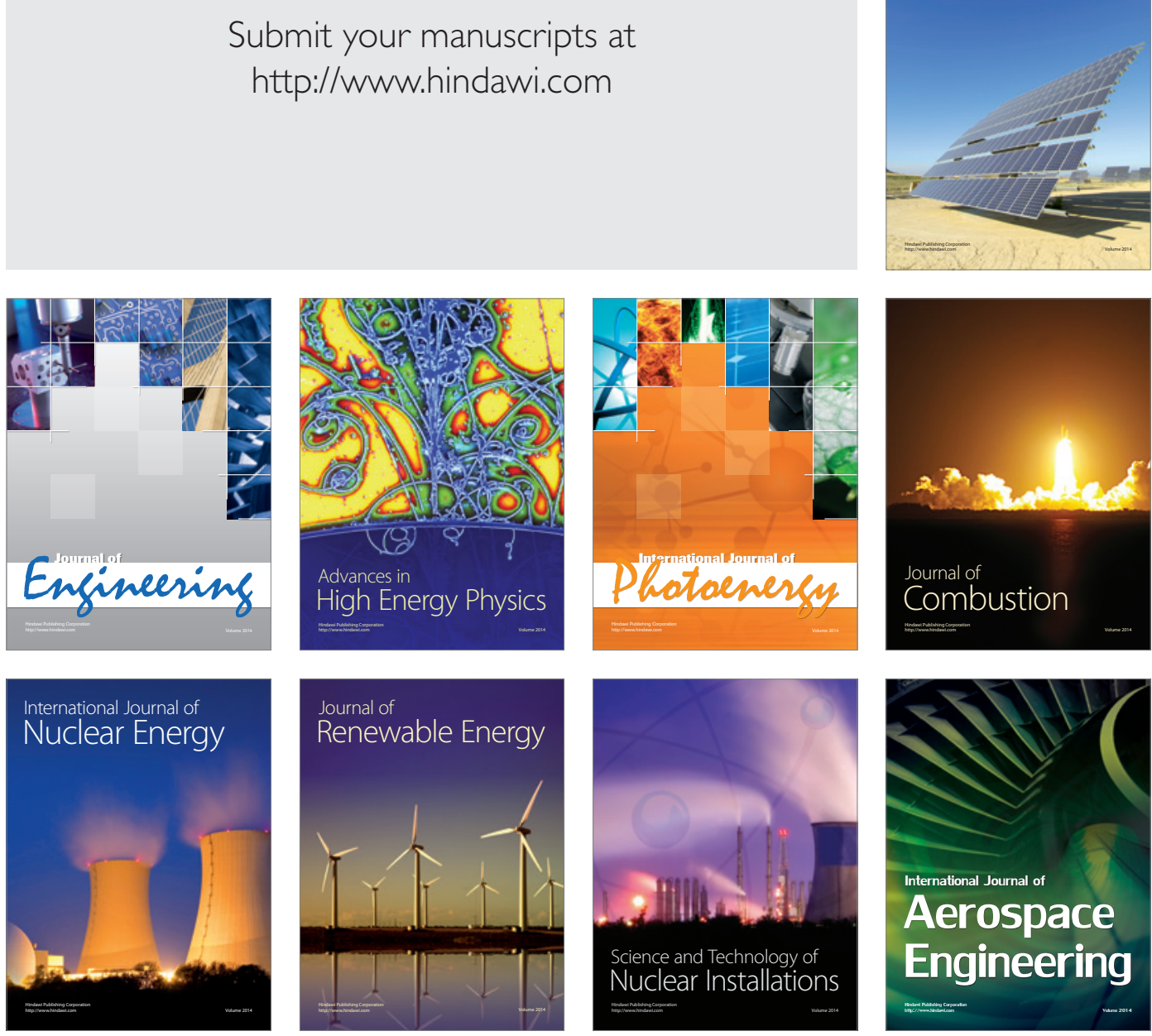